ISBN 978-93-84468-94-1

International Conference on Education, Business and Management (ICEBM-2017)

Bali (Indonesia) Jan. 8-9, 2017

\title{
Key Performance Indicators to Achieve Sustainability in Carica Micro Enterprises in Wonosobo Dieng
}

\author{
Inaki Maulida Hakim ${ }^{1}$, Annisa Putri Nur Bahri ${ }^{2}$ \\ ${ }^{1,2}$ Department of Industrial Engineering, Faculty of Engineering, Universitas Indonesia
}

\begin{abstract}
Micro, small, and medium enterprises (SMEs) have a vital role in the growth of economy in Indonesia, both in terms of contribution to GDP and creation of employment opportunities. They also should facing global challenges, which are respond to business opportunities and maintain their business to achieve sustainability. But, most of them haven't paid attention to sustainability aspects and have some problems to measure their sustainability achievement. Performance measurement should be conducted to know the situation and position of the business. This paper proposes a set of Key Performance Indicators (KPIs) for evaluating sustainable business believed to be appropriate to the micro enterprises carica industry in Wonosobo Dieng based on the triple bottom line of sustainability, which are economy, social, and environment. KPIs enables and assists micro enterprises carica industry to achieve the higher performance so as to increase the competitiveness for them to achieve sustainability.
\end{abstract}

Keywords: sustainability, key performance indicators, SMEs, analytical hierarchy process

\section{Introduction}

SMEs have a vital role in growth of economy in Indonesia, as they have been the main source of income to GDP, creation employment and product distribution. The number of SMEs in Indonesia amounted to $99.9 \%$ of the total business, give a contribution to Indonesia's GDP as much as $59.08 \%$ and create employment as much as $97.16 \%$. But, the contribution of SMEs to GDP is still rather low compared to the corporation. In addition to maintaining a great contribution to the country, SMEs also have to face two global challenges, which are respond to business opportunities opened up by globalization and create and maintain micro-enterprise business to grow its business reached sustainability (Anton, S. et al, 2015).

SMEs in Indonesia still have many problems. Those problems include difficulties in obtaining information and access to many things that caused business processes of SMEs are not optimal. The limited managerial capacity of organizations, low quality of human resources, and low productivity are other problems in SMEs. In addition, there are still many businesses that do not use technology and information in production and marketing system, so that SMEs have low competitiveness in the industry. From all the existing problems, it can be concluded that SMEs still do not pay attention to the sustainability of their business. Sustainability of SMEs is largely determined by the sustainability of the business itself and the government as a policyholder. To be able to compete in the era of globalization, SMEs requires a series of appropriate strategies based on sustainability and then implemented in their business. Before formulating the strategy, conditions and business positions should be determined by measurement of performance (Anton, S. et al, 2015). The functions of performance measurement are 
checking position, communicating position with shareholders, customers, or employee, confirm priorities, and compel progress to improve performance.

This paper proposes a set of Key Performance Indicators (KPIs) for evaluating sustainable business believed to be appropriate to the micro enterprises carica industry in Wonosobo Dieng based on the triple bottom line of sustainability, which are economic, social, and environmental. Carica industry is also a potential business because its uniqueness, which the fruits grow in certain areas, and Dieng is an area of conservation and tourism site. This research uses Analytical Hierarchy Process (AHP) for weighting the KPIs. KPIs enables and assists micro enterprises carica industry in achieving the higher performance so as to increase the competitiveness for them to achieve sustainability.

\section{Methodology}

There are several steps that used in this research, these steps are :

1. Determined the initial key performance indicators (KPIs) based on sustainability aspects for sustainable business was derived from literature.

2. Measure the importance level of each KPIs of sustainable business in carica micro enterprises. A total of 8 owners of carica micro enterprises were asked to rate the importance level of each KPIs.

3. The questionnaire was validated by expert and conduct interviews with owners, employees, and customers of carica micro enterprises.

4. Determined the formula and the expected value of each of the KPIs that derived from the literature.

5. Conduct the validity and reliability test of the employees and customers questionnaire results using SPSS. All the questions, both customers and employees questionnaires are valid and reliable because the value of $\mathrm{KMO}>0.5$ and croanbach's alpha $>0.6$.

6. Construct the hierarchy. The proposed KPIs are used in constructing a hierarchy defined in three groups including goal, perspectives, and indicators.

7. Make a pairwise comparison matrix between perspectives. A total of 8 owners of carica micro enterprises were asked to give their preferences on the KPIs with a scale of 1 to 9 (1=equal importance, $3=$ moderate importance, $5=$ strong importance, $7=$ very strong importance, $9=$ extreme importance).

8. Check the consistency of the hierarchy. If the value of Consistency Ratio (CR) is smaller or equal to $10 \%$, the inconsistency is acceptable, but if it is greater than $10 \%$, the judgment should be revised.

9. Measure performance of carica micro enterprises based on KPIs and compares the measurement value with the expected value.

10. Rate the KPIs with a scale range from 1 to 10 to assess performance of each the KPIs and compute the carica micro enterprises' score.

11. Conduct analysis with SWOT analysis to review internal strengths (S) and weaknesses (W) then the external opportunities $(\mathrm{O})$ and threats $(\mathrm{T})$ that may affect the business.

12. Make a strategies based on SO, ST, WO, and WT strategy to use in carica micro enterprises.

\section{Results}

This study starts with the development of initial KPIs consist of three factors (economic, social, environmental) divided into fifteen indicators were identified and derived from the literature. Fifteen indicators then validated by interviews conducted to owners of carica micro enterprise. A total of eight owners of carica micro enterprises were asked to rate the importance level of each KPIs, a five point likert scale ranging from 1 (not important at all) to 5 (very important) was used to rate the perspective of owners to the importance level of the KPIs and the result of mean importance values presented in Table I. It can be concluded that two indicators were removed from initial KPIs due to the less importance and thirteen indicators are proposed as the KPIs for sustainable business of carica micro enterprises. 
Conducted the interviews to eight owners of carica micro enterprises to obtain the required data. Besides, authors also spread the questionnaires to the employees and customers to get an insight and obtain the supporting data. To know sustainability achievement of the business, the formula and the expected value of each of the KPIs are identified and derived from the literature. All the collected data will be processed to get the actual values of the carica micro enterprises for each KPIs and these values will be used as performance measurement for further analysis.

TABLE I: Mean importance values of the initial KPIs

\begin{tabular}{clc}
\hline \hline Perspectives & \multicolumn{1}{c}{ Indicators } & Mean \\
\hline \multirow{5}{*}{ Economic } & Increase profitability & 4.875 \\
& Increase product sales & 5 \\
& Product innovation & 4.75 \\
& Incident investment & 4.5 \\
& Increase IT usage & 4.5 \\
& Employee satisfaction & 4.625 \\
& Product quality & 4.875 \\
& Employee welfare & 4.75 \\
& Customer satisfaction & 4.875 \\
& Increase quality of information system & 4.875 \\
& Number of injuries & 4.5 \\
& Electricity cost & 4.125 \\
Environmental & Total waste & 2.625 \\
& Use of equipment and raw materials & 3.875 \\
& Customer perception about environmentally-friendly image & 4.875 \\
\hline \hline
\end{tabular}

Answered questionnaires are needed to conduct the test for its validity and reliability. All the questions, both customers and employees questionnaires are valid and reliable if the value of KMO $>0.5$ and croanbach's alpha $>0.6$. In this case, all the answered questionnaires are valid and reliable. To weighting the KPIs, this research uses Analytical Hierarchy Process (AHP) and done by Expert Choice software. First of all, the hierarchy is being constructed to determine the goal, criteria consists of perspectives, which are economic, social, and environmental, and sub-criteria consists of the indicators that described each of factor as seen in Figure 1. 


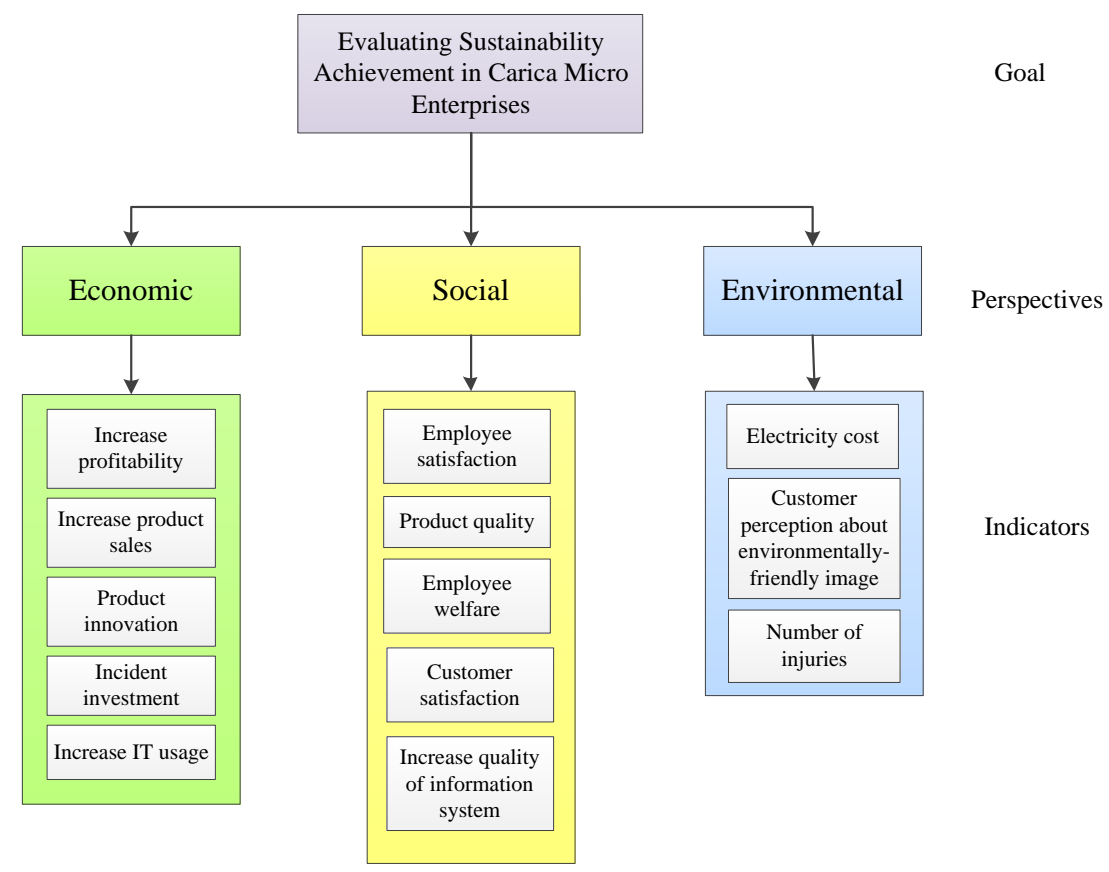

Fig. 1: The hierarchy structure of KPIs

KPIs are weighting the criteria and sub criteria by conduct a pairwise comparison between perspectives. A total of 8 owners of carica micro enterprises were asked to give their preferences on the KPIs with a scale of 1 to 9 (1=equal importance, $3=$ moderate importance, $5=$ strong importance, $7=$ very strong importance, $9=$ extreme importance) and then the results are processed with Expert Choice software to get both local and global weight as seen in Table II. After weighting the KPIs, authors compare the measurement value with the expected value and rate the KPIs with a scale range from 1 to 10 to assess performance of each the KPIs to compute the carica micro enterprises' score. If scores $\leq 4$ then performance level is poor, if $4<$ scores $\leq 7$, then performance level is fair, if $7<$ scores $\leq 9$, then performance level is good, if scores $>9$, then performance level is excellent. The score of carica micro enterprises presented in Table III.

TABLE II: Mean importance values of the initial KPIs

\begin{tabular}{|c|c|c|c|}
\hline Perspectives & Weight & Indicators & Weight \\
\hline \multirow{5}{*}{ Economic } & \multirow{5}{*}{0.391} & Increase profitability & 0.103 \\
\hline & & Increase product sales & 0.075 \\
\hline & & Product innovation & 0.081 \\
\hline & & Incident investment & 0.074 \\
\hline & & Increase IT usage & 0.058 \\
\hline \multirow{5}{*}{ Social } & \multirow{5}{*}{0.375} & Employee satisfaction & 0.081 \\
\hline & & Product quality & 0.074 \\
\hline & & Employee welfare & 0.077 \\
\hline & & Customer satisfaction & 0.076 \\
\hline & & Increase quality of information system & 0.068 \\
\hline \multirow{3}{*}{ Environmental } & \multirow{3}{*}{0.234} & Number of injuries & 0.113 \\
\hline & & Electricity cost & 0.056 \\
\hline & & Customer perception about environmentally-friendly image & 0.066 \\
\hline
\end{tabular}


TABLE III: The overall score of carica micro enterprises

\begin{tabular}{|c|c|c|c|c|c|}
\hline \multicolumn{5}{|c|}{ Economic } & \multirow{2}{*}{$\begin{array}{l}\text { Overall } \\
\text { Score }\end{array}$} \\
\hline Indicators & Weight & Rating & Score & Total Score & \\
\hline Increase profitability & 0.263 & 9 & 2.367 & \multirow{5}{*}{6.284} & \multirow{15}{*}{6.418} \\
\hline Increase product sales & 0.192 & 10 & 1.92 & & \\
\hline Product innovation & 0.208 & 3 & 0.624 & & \\
\hline Incident investment & 0.189 & 1 & 0.189 & & \\
\hline Increase IT usage & 0.148 & 8 & 1.184 & & \\
\hline \multicolumn{5}{|c|}{ Social } & \\
\hline Employee satisfaction & 0.215 & 2 & 0.43 & \multirow{6}{*}{4.999} & \\
\hline Product quality & 0.196 & 7 & 1.372 & & \\
\hline Employee welfare & 0.205 & 9 & 1.845 & & \\
\hline Customer satisfaction & 0.203 & 4 & 0.812 & & \\
\hline \multirow[t]{2}{*}{ Increase quality of information system } & 0.18 & 3 & 0.54 & & \\
\hline & ntal & & & & \\
\hline Number of injuries & 0.482 & 10 & 4.82 & \multirow{3}{*}{7.97} & \\
\hline Electricity cost & 0.238 & 5 & 1.19 & & \\
\hline $\begin{array}{l}\text { Customer perception about environmentally- } \\
\text { friendly image }\end{array}$ & 0.28 & 7 & 1.96 & & \\
\hline
\end{tabular}

\section{Discussion}

Carica micro enterprises have been evaluated and computed their score, both individual perspective's score and overall score are presented in Table 3. It can be seen that micro enterprises has attained the score about 6.418 which the level performance is fair. In order to achieve sustainability, carica micro enterprises have to formulate strategies to improve their performance based on KPIs from each perspectives. In this case, authors conduct SWOT analysis to review internal and external aspects that may affect the business and also analyze strategies that should be used in carica micro enterprises.

There are some strategies to help carica micro enterprises achieve sustainability, which are increase the usage of technology in product sales, increase product innovation based on flavor, packaging, and dimension, expand product distribution channel, use digital marketing, give a reward for employee that innovate product, and create vision, mission, and strategies for their sustainable business in the future.

\section{Conclusion}

SMEs contribution is considerably high in economic growth in Indonesia and sustainability aspects become very important for sustainable business of SMEs. This paper has developed a set of key performance indicators (KPIs) for sustainable business of carica micro enterprises. Fifteen indicators of the initial KPIs has been modified to thirteen KPIs for sustainable business of carica micro enterprises. Analytical Hierarchy Process (AHP) is used for weighting the importance of each KPIs by pairwise comparison. Sustainability performance measurement is conducted due to finding out about sustainability achievement and so the micro enterprises expected to pay attention to sustainability issues. Besides the KPIs, authors also create strategies for carica micro enterprises to achieve a sustainable business.

\section{Acknowledgements}

The authors would like to express their gratitude and appreciation to Universitas Indonesia for financing this research through Hibah Pengabdian Masyarakat Kolaborasi DRPM Universitas Indonesia 
and thanks to our experts that have been involved in our research and to our respondents which gave us every data we needed. We also gratefully acknowledge carica micro enterprises in Patakbanteng, Dieng.

\section{References}

[1] Amrina, E., Vilsi, A., "Key performance indicators for sustainable manufacturing evaluation in cement industry," in12th Global Conference on Sustainable Manufacturing, 2015, pp. 19 - 23.

[2] Anton, S., Muzakan, I., Muhammad, W., Sidiq, N.,"An assessment of SME competitiveness in Indonesia," in Journal of Competitiveness : Vol 7, 2015, pp 60-74.

[3] Benoit, C., Niederman, G. "Social sustainability assessment literature review," in2011 Sustainaibility Consortium, 2011.

[4] Ciasullo, M., Troisi, O., "The creation of sustainable value in SMEs: a case study," in14th Toulon-Verona Conference "Organizational Excellence in Services", 2011, pp. 291-317.

[5] Dalalah D. et al,"Application of the Analytic Hierarchy Process (AHP) in multi-criteria analysis of the selection of cranes," inJordan Journal of Mechanical and Industrial Engineering : Vol 4, 2010, pp. $567-578$.

[6] Fatimah et al.,"Sustainable manufacturing for Indonesian small and medium-sized enterprises (SMEs): the case of remanufactured alternators," inJournal of Remanufacturing, 2013, pp. 3-6.

[7] Hakim, M.I, Ibrahim, A. R., "Strategies for increasing the performance of micro, small, and medium enterprise (SME) in the apparel industry in Jakarta to achieve sustainability," in 8th Widyatama International Seminar on Sustainability, 2016, pp. 59-63.

[8] Mbizi, R., Hove L., Thondhlana, A., Kakava, N.,"Innovation in SMEs : a review of its role to organizational performance and smes operations sustainability," inInterdisciplinary Journal of Contemporary Research in Business : Vol 4, No 11, 2013.

[9] Mertens, G. et al.,"KPIs and sustainability performance,”Shareholder Support,2012.

[10] Pandya, V., "Comparative analysis of development of SMEs in developed and developing countries," inThe 2012 International Conference on Business and Management, 2012.

[11] $\mathrm{Wu}, \mathrm{D} .$, "Measuring performance in small and medium enterprises in the information \& communication technology industries," Dissertation, School of Management,RMIT University, Melbourne, Australia, 2009.

[12] Yilmaz, K., Altinkurt, Y., Cokluk, O., "Developing the educational belief scale : the validity and reliability study,"in Educational Sciences : Theory \& Practice - 11, 2011, pp. 343-350 